\title{
Una aproximación crítico-contextual al declive de la democracia en la era neoliberal
}

\author{
A critical-contextual approach to the decline \\ of democracy in the neoliberal era
}

\author{
EDUARDO ALVARADO-ESPINA \\ Universidad de Chile \\ Universidad Complutense de Madrid
}

\section{Cómo citar/Citation}

Alvarado-Espina, E. (2018). Una aproximación crítico-contextual al declive de la democracia en la era neoliberal. Revista Española de Ciencia Política, 47, 69-91. Doi: https://doi.org/10.21308/recp.47.03

\section{Resumen}

Este artículo propone una interpretación crítico-contextual para explicar el declive de la democracia en la era neoliberal. Para ello, se repasan y discuten en primer lugar las principales premisas de las teorías liberal y postmarxista de la democracia. En segundo lugar, se elabora un concepto sustantivo de la democracia combinando los elementos centrales del pluralismo liberal y del pluralismo agonista (igualdad política, pluralismo político y rendición de cuentas). Por último, utilizando este concepto como marco de análisis, se establecen dos dimensiones contextuales que definen a la democracia como sistema político: la cultura dominante (ideología) y la estructura social (desigualdad). A partir de este esquema teórico, se establece que la democracia, como sistema que articula la vida política, resulta disfuncional a una sociedad con un ideario neoliberal. Esta conclusión se sostiene en tres elementos que en la práctica desvirtúan la democracia: a) la libertad neoliberal, que hace más elitista el proceso de toma de decisiones; b) el Estado neoliberal, que desvincula el debate sobre el sistema económico de los ámbitos político y social, y c) la economía neoliberal, que acrecienta una desigualdad que causa la (auto) exclusión del sistema político de los individuos con menores recursos materiales.

Palabras clave: democracia, liberalismo, postmarxismo, pluralismo agonista, ideología, desigualdad.

\begin{abstract}
This article proposes a critical-contextual interpretation to explain the decline of democracy in the neoliberal era. To that aim the main premises of the liberal and post-Marxist theories
\end{abstract}


of democracy are first reviewed and discussed. Secondly, a substantive concept of democracy is built by combining the central elements of liberal pluralism and agonist pluralism (political equality, political pluralism and accountability). Finally, using this concept as a framework for analysis, two contextual dimensions are established that affect democracy as a political system: dominant culture (ideology) and social structure (inequality). From this theoretical framework, it is established that democracy, as a system that articulates political life, is dysfunctional to a society with a neoliberal ideology. This conclusion is based on three elements that distort democracy in practice: a) neoliberal freedom, which leads to a more elitist decision-making process; b) neoliberal State, which disassociates the debate on the economic system from the political and social spheres; and c) neoliberal economy, which increases inequality and makes individuals with less material resources to exclude themselves from the political system.

Keywords: democracy, liberalism, post-marxism, agonist pluralism, ideology, inequality.

\section{INTRODUCCIÓN}

¿Qué es la democracia actualmente? Esta pregunta no tiene una respuesta sencilla. Ni siquiera en la literatura especializada existe consenso respecto a su significado. Aún más hoy, cuando abundan diversos significantes y tipos de democracia. Por esta razón, la democracia tiende a considerarse como un concepto polisémico y controvertido. A esto se suma la continua disputa acerca del alcance y vigencia de este régimen político entre quienes asocian su funcionamiento a la prevalencia de un consenso racional de la clase dirigente (tesis elitistas) y aquellos que lo vinculan a la inclusión de los movimientos de protesta social (tesis populistas).

A pesar de las diferencias sobre el concepto, existe un amplio consenso respecto a que la democracia es un régimen que se ha extendido ampliamente por el mundo en las últimas tres décadas. Según The Economist (2016), en la actualidad 76 países, que representan el $49 \%$ de la población mundial, pueden ser considerados democráticos en diferentes grados - full democracies and flawed democracies-. Esto es el doble de los que había en la década de los setenta, por lo que el éxito de la democracia en términos cuantitativos resulta impresionante. Un éxito que ciertamente palidece cuando se compara con la propagación del capitalismo durante el mismo período (Merkel, 2014).

La prosperidad democrática resulta paradójica debido a que ha permitido la preeminencia de los intereses de poderosos grupos económicos sobre los del conjunto de la población (Offe, 1990; Crouch, 2004). Este hecho comporta un intercambio de roles entre lo político y lo no político (Beck, 1998) que erosiona los vasos comunicantes de los dos componentes básicos de la democracia - la representación política y la soberanía popular-, al tiempo que extiende «una idea de democracia a la que se despoja de su componente popular, alejándola del demos» (Mair, 2015: 21). Todo ello, por lo demás, estaría consolidando el clivaje de élites versus pueblo (Barreiro, 2015; Fundación Alternativas, 2015). 
De lo anterior se desprende que la crítica a las actuales democracias radica primordialmente en el modo en que se adoptan las decisiones políticas, las cuales se adecúan a una «forma de interacción privatizada entre gobiernos elegidos y élites» (Jörke, 2008: 143). A ello se suma «la tendencia dominante en nuestros días de considerar la democracia de una forma que la identifica casi exclusivamente con el Rechtsstaat (estado de derecho) y la defensa de los derechos humanos, dejando a un lado el elemento de la soberanía popular, que es juzgado obsoleto» (Mouffe, 2012: 21).

Por estos motivos, y aunque siga siendo la forma de gobierno preferida para una amplia mayoría de la población (Norris, 2011), y considerada un valor universal (Sen, 2006) y un ideal sin rival (Rosanvallon, 2006), se ha instalado la sensación de que la democracia está inmersa en un proceso de declive que pone en cuestión su alcance real $\mathrm{y}$ vigencia. A dicho declive parece contribuir el cambio de reglas de juego que ha redefinido la relación entre Estado, sociedad y economía: Un cambio que desdibuja el marco de referencia de la democracia, «en cuyo interior el mercado actúa ya como el gran integrador a costa del Estado y de las instituciones sociales, y donde el Estado social, despojado de sus atributos, tiende a transformarse en última instancia en un aparato jurídico encargado, ante todo, de garantizar los derechos de la propiedad» (Hermet, 2008: 64).

Estas reglas, a su vez, reflejan la extensión estructural de un metarrelato que, fundado en las ideas neoclásicas de liberalización de los mercados, flexibilización laboral, ajuste fiscal y desregulación financiera, se ha apropiado de las instituciones políticas nacionales e internacionales (Keane, 1992; Stiglitz, 2011). Una ideologia que se despliega como hegemonía global gracias a ciertos hitos que brindan un nuevo contorno al mapa geopolítico de finales del siglo xx —Consenso de Washington, caída del Muro de Berlín, desmembramiento de la URSS y Tratado de Maastricht-. Hitos que marcan el punto de partida de profundos cambios políticos y económicos en los países de América Latina, del Este de Europa y de la Unión Europea, y que dan forma a lo que Roberts (2002) llama la era neoliberal.

A pesar de estos hechos, hay autores que rechazan cualquier visión pesimista sobre el actual estado de la democracia. Por ejemplo, Battison (2011), Schmitter (2015) y Levitsky y Way (2015) no solo matizan, sino que rechazan de plano la aseveración de que la democracia esté en declive. Comparten que esté en crisis, pero sostienen que ello representa más bien un momento de transición desde un tipo de democracia a otro aún desconocido. Como argumenta Schmitter (2015:35) «la actual incertidumbre sobre las reglas del juego es la característica predominante en todas las situaciones de transición». Es decir, la democracia avanza pero no se tiene certeza de hacia dónde.

De esta forma, el debate sobre el estado de la democracia deviene inexorablemente en el choque de dos enfoques de análisis: los sustanciales y los formales. Para los primeros, la democracia muestra graves problemas para armonizar representación política y soberanía popular, como resultado de la prevalencia de los intereses de las élites económicas en el proceso de toma de decisiones. En cambio, para los segundos, que los gobernantes sean seleccionados mediante elecciones periódicas, libres y justas, que exista una competencia regular por el poder entre dos o más partidos, y que las 
resoluciones políticas del Estado sean acatadas, es suficiente para afirmar la total vigencia de la democracia.

Aunque este debate no es nuevo, aquí se parte de la premisa de que los problemas para conseguir que la democracia sea el reflejo de lo que Kelsen (1980) llamó «la identidad de dirigentes y dirigidos", no habían sido tan evidentes ni tan desconcertantes como lo son ahora, en la sociedad del capitalismo de mercado (Streeck, 2011).

Partiendo de esta premisa, este artículo desarrolla un enfoque crítico-contextual de la democracia, con el fin de reinterpretar su crisis en la era neoliberal a través de dos dimensiones contextuales, la ideológica y la estructural. Para ello, en el primer apartado se exponen y discuten las dos principales teorías de la democracia, la liberal y la postmarxista. En el segundo, y a partir de esta discusión téorica, se fija un marco conceptual que da cobertura epistémica al análisis, mediante una definición sustancial y sistémica de la democracia. En el tercero, se aplica el marco conceptual atribuyendo al contexto -ideología y estructura social — un papel central para entender el declive de la democracia tal cual la conocemos. Por último, en el cuarto apartado se ofrecen algunas conclusiones y se plantean algunos desafíos respecto a la democracia.

\section{DEL LIBERALISMO AL POSTMARXISMO}

En términos etimológicos la democracia es el gobierno del pueblo. Esta simple y popular definición domicilia la fuente de legitimidad del poder político en la soberanía popular, en el demos. De acuerdo con esto, «el poder solo es legítimo cuando su investidura viene de abajo, solo si emana de la voluntad popular [...] libremente consentida» (Sartori, 2003: 87). Una legitimidad que es posteriormente revolucionada por el Estado de derecho. Con la incorporación de este artefacto jurídico, el poder obtenido por medio de la fuerza bruta o basado en el dominio de una clase social queda deslegitimado (Habermas, 1999). En otras palabras, el Estado de derecho hace de la democracia un juego reglado donde quienes compiten por el poder político deben persuadir a los ciudadanos para conseguir un siempre eventual consentimiento mayoritario. En términos formales, el Estado de derecho es la base de legitimidad del poder en una democracia, la razón por la cual los representantes políticos gozan, en su forma moderna, de la auctoritas para gobernar.

Sin embargo, la democracia, aparte de ser el gobierno del pueblo, se caracteriza, como régimen e ideal político, por unos procesos, contenidos y objetivos que desbordan el estrecho margen de su etimología y legalidad. A causa de ello, esta se ha analizado, descrito e idealizado recurriendo a diversas metodologías y puntos de vista, desde modelos comparados a estudios de caso; desde enfoques descriptivos a prescriptivos. También se le ha tratado indistintamente como método, estrategia, proyecto o fin, y construido una variada tipología para explicar tanto sus peculiaridades nacionales, como la cultura democrática de diferentes zonas geográficas.

En una primera aproximación a estas cuestiones, se exponen y discuten los principales postulados de dos teorías aparentemente contrapuestas, la liberal (económica y 
pluralista) y la postmarxista (radical-agonista). La principal distinción entre ellas es que los liberales circunscriben la democracia a la composición y funcionamiento de las instituciones de representación y gobierno - la política-, mientras que los postmarxistas la amplían al ejercicio inclusivo de la soberanía popular — lo político- sin esencialismos.

\section{Teoría liberal-económica de la democracia}

En la tradición liberal, la democracia se concibe como «un conjunto de reglas que permiten tomar decisiones colectivas, vale decir, decisiones que se refieren a toda una colectividad, con el mayor consenso posible de las personas a las que estas decisiones se aplicarán» (Bobbio, 1986: 127). La piedra angular de estas decisiones "es la libre elección de los gobernantes por los gobernados» (Touraine, 1991: 274). En esta premisa básica del pensamiento político liberal, la democracia no es más que una forma de gobierno opuesta a todo tipo de autocracia, como el absolutismo, el totalitarismo o la dictadura.

Para la teoría liberal-económica, también denominada criticamente elitismo democrático (véanse Bachrach, 1973; Ruiz, 1992; Best y Higley, 2010), la democracia está acotada a un «arreglo institucional para llegar a decisiones políticas en la que los individuos adquieren el poder de decidir mediante una lucha competitiva por el voto de la población» (Schumpeter, 2008: 269). En esta lucha, la participación política se supedita a la institucionalidad, para así evitar lo que Huntington (1991a) llama los excesos democráticos de las masas. En este marco, la democracia es básicamente la "oportunidad con que cuenta el pueblo para aceptar o rechazar a los hombres que han de gobernarlo» (Schumpeter, 2008: 285); un medio para regular la competencia entre oligarquías, donde el pueblo solamente interviene para dirimir la contienda electoral (Przeworski, 1991).

A partir de estos postulados, se desarrolla toda una coriente elitista de la democracia que desdeña la participación popular y no reconoce la existencia de cierres económicos, sociales y políticos que puedan restringir el acceso a las instituciones representativas de grupos e individuos socialmente excluidos o que carezcan de la expertise que impone la profesionalización y tecnificación de la política (veánse, por ejemplo, los trabajos de Hungtinton, 1991b; Everson, 2000; Peters, 2003; Thatcher y Stone Sweet, 2003). Esta interpretación, que se identifica mayoritariamente con la public choice theory, limita la gobernanza democrática a la buena gestión de la economía y la eficiencia — reducción- del gasto público.

Otro aspecto característico de esta teoría es su carácter positivista. En este sentido, distingue la labor del Gobierno a la del resto de la sociedad, otorgándole especificidad a su función en la división del trabajo. Esto quiere decir que la política se considera una actividad que requiere de organizaciones especializadas en el arte de gobernar y la gestión del Estado. Desde este prisma, la democracia es equiparable a un juego político en el que los individuos seleccionan a quienes gobiernan siguiendo un patrón racional de consumo, que es la base del modelo de elección racional de Downs (1973). 
Por último, la perspectiva liberal privilegia los mecanismos de la representación sobre otras facetas de la democracia. Es lo que hace Sartori (2008: 27) cuando postula que «la democracia representativa es la mejor solución para resolver el problema del ejercicio y la transmisión del poder». En estos términos, la política se circunscribe exclusivamente a una adición de intereses y a la obligación del representante a responder. Esa obligación — la de responder- hace referencia al control electoral que pueden ejercer los ciudadanos sobre los políticos. Una manera de refrendar la legitimidad fundada en el supuesto liberal de que todos los miembros de la sociedad, a priori, gozan de igualdad en el ejercicio de sus derechos políticos.

En síntesis, la teoría liberal entiende la democracia como una forma de regular el conflicto entre diferentes intereses (Mouffe, 2012), así como un orden del egoísmo, donde priman la libertad de expresión y la propiedad privada, pero no la inclusión política de todos los grupos sociales de la población (Dunn, 2005).

\section{Teoría pluralista de la democracia}

Para la teoría pluralista, la convergencia de las élites es el núcleo fundante de la democracia real; la base del sistema político posible (Sartori, 1987), mientras que la igualdad de oportunidades - o de trato- es el elemento central para poder oponerse al Gobierno de turno y actuar como contrapeso al poder político (Dahl, 1997). Por consiguiente, no se concibe la existencia de grupos que tengan mayor poder que otros, ni que la desigualdad social sea relevante para el proceso de conformación del poder político.

Para el pluralismo, la sociedad se compone de diferentes grupos, entre los cuales se reparte y difumina el poder. Esto es, élites — políticas, económicas, culturales, sociales, jurídicas - entre las cuales el poder se distribuye de manera equilibrada y no jerárquica. $Y$ aunque se asume que los recursos «están distribuidos de forma desigual entre un abanico de grupos y élites, resulta imposible que una sola clase o interés domine la sociedad» (Smith, 1997: 221).

En lo que respecta a la participación política del pueblo, se considera positiva en tanto se dé en los términos de un pluralismo razonable y cooperativo (Rawls, 1996). Esto constrińe la democracia a un paradigma de racionalismo institucional, donde los ciudadanos tienen nominalmente las mismas posibilidades de influir en y acceder a las instituciones de gobierno y representación. ¿Pero tienen efectivamente los ciudadanos la misma posibilidad de controlar a sus representantes u optar a ser uno de ellos? En realidad, no la tienen. De hecho, Dahl afirma «que la participación y competencia política posibilite un cambio en la composición política de los dirigentes [...] no equivale a afirmar que los dirigentes políticos y los parlamentos sean siempre una muestra representativa de los diferentes estratos sociológicos, ocupacionales y demás agrupaciones de la sociedad. No lo son nunca» (1997: 29-31).

Los pluralistas además sostienen que mediante el reclutamiento o la cooptación de las élites se consigue que individuos de diversos sectores sociales se incorporen a la vida 
política. Esto impide que los círculos de poder estén definidos exclusivamente por el origen social de sus miembros. Esta aseveración resta importancia a los grandes contrastes que existen entre ricos y pobres, cuando se trata de influir en el diseño de las políticas públicas. En otras palabras, se oculta la organización y fuerza que tienen los ricos para condicionar políticamente al resto de la sociedad. En esta línea, un pluralista como Finer (1966) fue más allá equiparando el poder de las asociaciones pobres al de las organizaciones empresariales, en cuanto a su capacidad de influir en las políticas públicas.

Respecto a la democracia, la principal tesis pluralista es que, al ser un sistema abierto, la contradicción de intereses y la capacidad para ejercer presión se contrarrestan, creando un equilibrio que tensa la cuerda del poder en ambos sentidos de igual modo. Por ejemplo, si los empresarios crean una asociación para velar por sus intereses, los sindicatos harán lo mismo para salvaguardar los suyos. No obstante, es evidente que los empresarios tienen una ventaja estructural al respecto. Incluso Dahl presupone que «los individuos que están muy bien situados para acceder a unos recursos suelen ser los peor situados para acceder a otros» (1961: 228). En términos más precisos, los grupos con mayores recursos financieros probablemente también sean los más limitados en cuanto a votos (Smith, 1997). No obstante, ante tal sentencia cabe preguntarse ¿qué impide que grupos con grandes recursos económicos consigan esos votos financiando campañas electorales, o la actividad misma de partidos políticos con opciones reales de gobernar?

Frente a este dilema, pluralistas como Lindblom (1997) y Dahl (2002) acabaron reconociendo que las élites corporativistas gozan de una posición predominante en las democracias capitalistas, lo que dificulta el equilibrio de poder esgrimido por el pluralismo. Aun así, para los pluralistas la clave de la supervivencia de la democracia está en la competencia entre las élites gobernantes (Bachrach, 1973).

Aunque el enfoque pluralista mantiene la misma interpretación procedimental y representativa de la democracia, logra distanciarse del enfoque liberal primigenio al reconocer la influencia de muchos y muy diferentes grupos (élites) en la acción del Gobierno. Eso sí, al igual que el viejo liberalismo elitista, recalca la necesidad de conseguir el consenso de esas élites en torno a la versión capitalista de la democracia.

\section{La democracia radical y el enfoque agonista}

La democracia radical bebe de la crítica que Gramsci (1975) elaboró a la interpretación economicista del marxismo, al no considerar la importancia que tiene el discurso dominante (la hegemonía) en la reproducción del sentido común del poder. Gramsci se opuso a reducir el antagonismo social a la lucha de clases promovida por la dialéctica capital/trabajo. En ese afán, amplió el análisis de las contradicciones sociales hacia lo que Marx y Engels definieron como la ideología dominante, que es la producción espiritual de los valores de quienes controlan los medios de producción material. Esto sería lo que permite a la clase dominante - los capitalistas - ejercer y disfrutar del poder político del Estado, mientras que la clase dominada - los obreros_- asume un rol subordinado y obediente ante tal poder (Marx y Engels, 1987). 
Para el enfoque radical, la democracia se instituye desde los antagonismos sociales construidos por lo político. En otros términos, la democracia se conforma a partir de la confrontación de intereses, valores e identidades, y no desde las instituciones políticas, tal como propone el racionalismo liberal (Mouffe, 1999; 2012). Son los factores externos al sistema político los que dan forma a la confrontación y al pluralismo político constitutivos de la democracia.

A diferencia de las perspectivas liberal y pluralista, que restringen la democracia a la selección de gobernantes y el check and balance, la democracia radical amplía el radio de acción de la democracia a la sociedad civil, a la organización social de lo político. Se entiende que la política, como práctica transformadora de las relaciones sociales, no puede instalarse en un nivel distinto de lo social, ya que el problema de lo político es el problema de la institución de lo social (Laclau y Mouffe, 1987).

Este enfoque apela a «una forma política que no se basa en la reivindicación dogmática de ninguna esencia de lo social, sino que encuentra su fundamento en la contingencia y ambigüedad de toda esencia, en el carácter constitutivo de la división social y el antagonismo" (ibid.: 239). Esto significa —en una abierta crítica al racionalismo liberal - que la democracia no se reduce a una agregación de procedimientos —elecciones libres, representación política, libertad de expresión, separación de poderes, sistema de partidos, multiplicidad de fuentes de información y respeto a los derechos humanos-. También involucra el reconocimiento de la pluralidad y los antagonismos político, cultural y social que interactúan en las sociedades heterogéneas. En este sentido, su desafío es «elaborar una forma verdaderamente política de liberalismo que, sin dejar de postular la defensa de los derechos y el principio de la libertad individual, no escamotee la cuestión del conflicto, el antagonismo y la decisión» (Mouffe, 1999: 12).

Además, con base en la construcción de un discurso de la adversidad o alteridad hegemónica, el enfoque radical y agonista abandona el cuadro hegemónico del consenso para trasladarse - como espacio preferente de la política — a la universalidad de la particularidad (Laclau y Mouffe, 1987). Lo mismo hace con la idea liberal de una sociedad preexistente de ciudadanos libres e iguales, pues sitúa en el terreno áspero de las luchas sociales lo que en justicia es la sociedad (Schaap, 2007).

En contraposición a la propuesta deliberativa de la democracia (véanse Habermas, 1989; 1992; Cohen, 2001), el agonismo democrático revindica el antagonismo entre adversarios, que hace de la política un espacio de representación de las particularidades para la construcción de nuevas esferas públicas (Laclau y Mouffe, 1987). En suma, defiende que la dinámica conflictiva del pluralismo permite representar tanto lo que está dentro como lo que está fuera de las instituciones de la política.

En esta misma línea, y contrariando el consenso moral racional, que Mouffe (2012) define como una fuerza de contracción de la democracia, el enfoque agonísta rivaliza con el consenso sin antagonismos abogado por la tercera vía entre capitalismo y socialismo propuesta por Giddens (1999). Para Mouffe, «la primera obligación de la política democrática no consiste en eliminar las pasiones de la esfera de lo público para hacer posible el consenso racional, sino en movilizar esas pasiones en la dirección de los 
objetivos democráticos» (2012: 116). Por tanto, el avance democrático pasa por la visibilización y gestión de las diferencias, no por su negación, elución o erradicación.

En síntesis, la teoría radical y agonista de la democracia alienta la creación y gestión de los antagonismos de toda índole como una etapa preformativa de la democracia. Así, recusa cualquier inclinación al consenso o cierre institucional de lo social y rehuye, sin cuestionar sus instituciones, del ideal filosófico del liberalismo.

\section{DEFINICIONES, PRINCIPIOS Y CONCEPTO SUSTANTIVO DE LA DEMOCRACIA}

Estas teorías también elaboran definiciones que guardan coherencia con la interpretación que se hace de la política, así como del comportamiento político promovido en la sociedad. De este modo, se pueden encontrar variadas definiciones de democracia. Eso sí, la mayor parte de ellas son escuetas descripciones procesales que facilitan su descomposición en requisitos o condiciones formales distinguibles para su observación.

Contrariamente a lo que se supone, estos requisitos tienden a estirarse excesivamente, perdiendo precisión y dando la impresión de que casi cualquier régimen que celebre elecciones periódicas y cuente con un sistema de partidos plural es, indefectiblemente, una democracia. En algunos casos, el problema de la elasticidad conceptual se ha soslayado incluyendo adjetivos descriptivos para hablar de tipos de democracia, como delegativa, limitada, tutelada, plebiscitaria, electoral o formal. También se ha recurrido, tras la democratización de dictaduras militares, a calificaciones como autoritaria, neopatrimonial, militarmente dominada y protodemocracia (Collier y Levitsky, 1997).

Siguiendo un hilo argumental estándar, las definiciones procesales de democracia se han centrado en la forma en que se selecciona el Gobierno —elecciones libres_-, la competencia electoral entre dos o más partidos y las garantías para el ejercicio de la ciudadanía política — derechos políticos y libertades civiles- - Unos elementos que pueden considerarse condiciones o exigencias mínimas para todo aquel régimen que pretenda erigirse como democrático. Este tipo de definiciones son las que abundan en una diversidad de trabajos y estudios sobre la democracia, como en los de Downs (1973), Diamond et al. (1990), Huntington (1991b) y Przeworski et al. (1996). O, más recientemente, en algunos estudios acerca de la calidad de la democracia, como el de Mainwaring y Pérez-Liñán (2015).

Un punto aparte merece la clásica descripción de poliarquía o gobierno de muchos — sinonimia de democracia representativa— de Robert Dahl (1997). En ella, Dahl atribuye ocho requisitos formales a la democracia ${ }^{1}$. Con esta caracterización se impuso

1. 1) Libertad de asociación; 2) libertad de expresión; 3) sufragio inclusivo; 4) elección de los cargos públicos; 5) derecho de los líderes políticos a competir en busca de apoyo; 6) diversidad de fuentes de información; 7) elecciones libres e imparciales, y 8) instituciones que garanticen que la política del Gobierno dependa de los votos y demás formas de expresar las preferencias. 
una idea más bien descriptiva y cuantificable de este régimen político. Es decir, hay democracia - o poliarquía - cuando se cumple con un listado de condiciones formales verificables. Factores sustanciales y cualitativos, como la igualdad social o la capacidad efectiva de la ciudadanía para controlar a los políticos, quedan fuera de esta caracterización.

Ahora bien, el propio Dahl (2002: 77) en un posterior trabajo parece intentar reparar este déficit interpretativo, al señalar que «el orden económico óptimo debería contribuir, entre otras cosas, a generar una distribución de los recursos políticos favorables a los objetivos de igualdad de voto, participación efectiva, comprensión informada y control final de la agenda política por todos los adultos sujetos a las leyes».

También existen otras acepciones que apelan a una idea más sustancial de la democracia. Entre ellas destacan las planteadas por Tilly, Mouffe y Morlino.

Si bien Tilly (2007) no desarrolla una definición como tal, sí describe cuatro componentes copulativos de la democracia: a) amplitud en la inclusión política de la gente bajo la jurisdicción del Estado —ciudadanía inclusiva—; b) igualdad dentro de y entre las categorías de ciudadanos -igualdad de derechos y deberes políticos y de derechos y libertades sin importar el origen de cada individuo-; c) protección frente a la arbitrariedad del Estado — debido proceso para todos los ciudadanos-, y d) consulta mutuamente vinculante - los agentes estatales disponen de obligaciones claras y responsabilidades ejecutables-. Por tanto, para Tilly «un régimen es democrático en la medida en que las relaciones políticas entre el Estado y sus ciudadanos se demuestran con consultas mutuamete vinculantes, amplias, iguales y protegidas» (ibid.: 45).

Mouffe define la democracia como un régimen político al que «le concierne el ordenamiento simbólico de las relaciones sociales [...] una forma específica de organizar políticamente la coexistencia humana» (2012: 36). Esto implica que la democracia es mucho más que una mera forma de gobierno (Mouffe, 2012). En tal sentido, hay que atribuirle la defensa del pluralismo, a partir del reconocimiento institucional de los antagonismos, y la garantía de igualdad de todos los ciudadanos antes, durante y después de los procesos de toma de decisión.

Por último, está la descripción de buena democracia de Morlino (2015). Una buena democracia es aquella donde los ciudadanos a) tienen satisfechas plenamente sus demandas; b) están dotados de una libertad e igualdad por encima de los mínimos, y c) gozan del poder de controlar y evaluar que los gobernantes cumplan con los compromisos adquiridos respecto a las demandas de la sociedad civil.

De acuerdo con estas tres últimas formulaciones, la esencia de la democracia viene conferida por su centralidad en la interacción entre política y sociedad. Desde esta centralidad, le corresponde la construcción continua de una ciudadanía inclusiva, mediante herramientas de receptividad que den respuesta efectiva a las demandas de los ciudadanos (O'Donnell et al., 2003). Por lo demás, si la democracia es por antonomasia un régimen político inclusivo (Offe, 1990; O'Donnell et al., 2003; Dahl, 2012), entonces no se pueden establecer diferencias en el tratamiento de la opinión, ni en los intereses de los ciudadanos. Tampoco distorsionar las preferencias políticas de individuos, grupos y colectivos sociales. 
Para armonizar la interacción entre política y sociedad y propiciar la acción inclusiva, la democracia ha de articularse en torno a tres principios o ejes normativos: igualdad política, pluralismo político y rendición de cuentas.

La igualdad política es un medio de autoprotección de la democracia. Esto se debe a que es una "condición necesaria de muchos otros valores importantes, incluida una de las libertades humanas más fundamentales: la de contribuir a determinar, en cooperación con otros, las leyes y normas que uno deberá obedecer» (Dahl, 2002: 7). También es una forma de evitar que los gobernados estén a merced de los poderosos (Vargas-Cullell, 2012). Es lo que democratiza la naturaleza elitista de la representación al hacer efectivo el derecho a sufragio activo y pasivo de todos los ciudadanos por igual. Por lo tanto, la igualdad política es a la vez componente y objetivo consustancial de la democracia (Dahl, 2008).

Respecto al pluralismo político, este no se limita a describir la composición del sistema de partidos, como proponen Sartori (1987) o Lijphart (1995), ni si acaso existe competencia electoral y alternancia en el Gobierno entre dos o más partidos políticos (Downs, 1973; Huntington, 1991a; Dahl, 1997). Si bien la presencia de una multiplicidad de partidos que representen la división de intereses, valores y opiniones de la sociedad (Przeworski, 1991) es primordial, el pluralismo político también implica reconocer la alteridad, al otro antagónico, que es de donde emanan esos intereses, valores e ideas diferentes. Lo que está inexorablemente vinculado al reconocimiento del disenso político que existe más allá de los muros institucionales. De esta forma, el pluralismo político fomenta un sistema de controles que pone trabas a la dominación social e ideológica. Como argumentan Dahl (1992) y Mouffe (1999), desde perspectivas distintas, muchas veces son las nociones de diferenciación y autonomía las que definen las relaciones entre los seres humanos.

Por último, puede decirse que la rendición de cuentas o accountability alude a un régimen de instituciones capaces de controlar a las élites y hacerlas más diversas (Dahl et al., 1999). En este sentido, Diamond (2003) — citando a O’Donnell— señala que para que un sistema político efectivamente rinda cuentas, requiere de tres componentes, el democrático, el liberal y el republicano. Esto significa que a) el sistema permite a los ciudadanos elegir a sus gobernantes, además de capacitarles para expresarse y participar en los procesos políticos; b) el Estado está impedido de invadir los derechos básicos de la personas, y c) existe una separación y equilibrio de poderes que proporciona un Estado de derecho y un buen gobierno a través de las instituciones de accountability horizontal, manteniendo la igualdad ante la ley de todos los actores, públicos y privados.

Sin embargo, para que ese control sea real, el Estado tiene que ser capaz de garantizar la capacidad de agencia de los ciudadanos de manera autónoma, plural, igualitaria y universal. En otros términos, para garantizar una rendición de cuentas se requiere de «un contexto social que incluya fuentes de información variadas, no monopolizadas o censuradas por el Estado. Esta posibilidad, que es un componente de un contexto socialmente diverso y plural, es un bien público respaldado por un sistema legal 
democrático y por el adecuado desempeño de las instituciones estatales» (O’Donnell et al., 2003: 84).

A tenor de lo hasta aquí expuesto y en función a los principios de igualdad política, pluralismo político y rendición de cuentas, en términos normativos la democracia se puede entender como un régimen político donde los representantes políticos son elegidos a través de elecciones libres, justas, periódicas y regladas; el Estado y el Gobierno garantizan el disfrute de los derechos políticos y sociales y las libertades civiles; el pluralismo político y social está representado en las instituciones; los procesos políticos son socialmente inclusivos; la relación entre el sistema político y la ciudadanía se basa en consultas permanentes y mutuamente vinculantes, y la toma de decisiones no está condicionada por el interés de grupo privilegiado alguno. Esta definición acoge tanto los aspectos formales de la democracia (elecciones, derechos, libertades) como sus aspectos sustanciales (pluralismo, igualdad política, accountability).

Por lo tanto, la democracia condensa la lucha entre fuerzas políticas, sociales y económicas antagónicas, promoviendo mecanismos para la resolución pacífica de los conflictos que derivan de esas contradicciones. Un espacio en el que se organizan los medios, contenidos y resultados de la disputa política, rebasando en muchas ocasiones los marcos institucionales fijados por el Estado. En otras palabras, la democracia tiene como misión articular la vida política, que no es otra cosa que «un sistema de conducta incorporado a un ambiente a cuyas influencias está expuesto el sistema político mismo, que a su turno reacciona frente a ellas» (Easton, 1965: 17).

\section{UNA INTERPRETACIÓN CRÍTICO-CONTEXTUAL DEL DECLIVE DE LA DEMOCRACIA EN LA ERA NEOLIBERAL}

La democracia, al ser un sistema que articula la vida política (O’Donnell, 1989), está estrechamente ligada a otros sistemas sociales, por lo que las dinámicas y paradigmas de estos necesariamente contaminan y condicionan su funcionamiento. Dicho de otro modo, la democracia es la expresión política de una determinada construcción social (clases), económica (recursos materiales) y cultural (recursos cognitivos). Por tal razón, no puede concebirse como un mero compartimento estanco de la política o, como promueve el dogma liberal, una especie de liturgia institucional en la que se participa a intervalos (períodos electorales) y circunscrita a un concepto instrumental y atemporal concordado al margen de toda conflictividad social (consenso de élites).

Conforme al marco conceptual popuesto, la democracia representa un objeto y sujeto social que debe ser analizado e interpretado, tal y como propone la teoría crítica, dentro de su contexto-social e histórico (Frankenberg, 2011). Es decir, atendiendo a que este es un sistema afectado por las contradicciones de intereses, valores e ideas provenientes de la estructura social y la división idelógica de cada época. Una premisa que se corrobora al contextualizar las diferentes interpretaciones que ha tenido este régimen político a lo largo del siglo xx. 
Así, la teoría económica o elitista de la democracia fue la respuesta liberal a la política de movilización de masas que proliferó en Europa y Estados Unidos después de la gran depresión económica de 1929. Por su parte, el enfoque pluralista, que surge entre las décadas de los cincuenta y sesenta, fue una exaltación de las bondades del régimen político de Estados Unidos frente al modelo de democracia popular propugnado por el comunismo durante la Guerra Fría. Por último, las interpretaciones postmarxistas de la democracia representan la reinvención del socialismo democrático, el cual bebe de dos fuentes: los valores de autoexpresión y el antagonismo social, ambas identificadas con los nuevos movimientos sociales que emergen tras la revolución de mayo de 1968.

Entonces, si para interpretar la democracia hay que atender a la influencia que ejercen el contexto y la estructura de las relaciones sociales, en su análisis hay que contemplar tres supuestos que la explican como constructo político, social y cultural.

En primer lugar, la democracia supone reconocer que el conflicto social, aún más en momentos de extrema politización, es lo que fija las divisiones expresivas y proyectivas de sus instituciones políticas. Este es el acto político puro, que de acuerdo a Zizek «es aquello que modifica el contexto en que el funcionan las cosas» (2009a: 32). Este acto no sucede al margen de la acción de la política y la economía - y viceversa-. Ejemplos de ello pueden ser la defensa de las libertades civiles o la lucha a favor de la equiparación de salarios entre hombres y mujeres. En ambos casos se expresa la tensión entre política y sociedad mediante un acto político que interpela a la acción del sistema político y económico. Así, acto y acción están correlacionados en sus consecuencias, provocando determinadas actitudes y reacciones respecto al funcionamiento de los dos sistemas. Una relación que es determinante para la proliferación de los valores democráticos.

Segundo, la democracia implica gobernar la inestabilidad. Al contrario de lo que opinan Rawls (1996) o Habermas (1992), la democracia se legitima cuando consigue dar continuidad a la lucha política por causes pacíficos en un océano de antagonismos. Este es el espacio de lo político, que es donde se aloja la soberanía popular. El lugar en el que fluyen las particularidades, que son las que otorgan el carácter democrático a toda sociedad. De esta forma, la negación de la lucha hegemónica como aspecto constitutivo de la política, supone una paulatina pérdida de legitimidad de las instituciones y valores democráticos para aquellos que son invalidados a priori en esa lucha.

Tercero, los procesos del sistema democrático están estrechamente vinculados a la convención ética y el sentido común o ideología dominante de cada época. Por tanto, «los procedimientos siempre implican compromisos éticos sustanciales, y nunca puede existir nada que se parezca a unos procedimientos puramente neutrales» (Mouffe, 2012: 110). De este modo, cuestiones prescriptivas, como la igualdad política, la justicia social o los derechos sociales no son ajenas a las formas que adoptan aquellas más descriptivas, como el pluralismo político, el sufragio universal o la libertad de expresión. Unas y otras interactúan de modo que los instrumentos vienen a ser el reflejo de los diferentes tipos de conflictos que dinamizan la sociedad. Esto no solo confiere a la democracia la capacidad de albergar, sino que también de fomentar la impugnación del propio orden social que gobierna. 
A partir de estos tres supuestos se podría explicar el declive de la democracia en muchos países occidentales. Esto implica sumergirse en un lugar abstracto, pero al mismo tiempo factual, en el que se articula representación política y soberanía popular, y que es donde "cabría esperar que la interacción ciudadana con los representantes políticos fuera más estrecha y activa» (Mair, 2015: 35).

Como se expone a continuación, este declive puede estar provocado tanto por la superestructura (ideología) como por la estructura social (desigualdad). Dos dimensiones contextuales que dan sentido, en téminos lacananianos, a la realidad y a lo real en la sociedad capitalista desde finales del siglo xx.

\section{Estado, discurso y valores antidemocráticos en la ideología neoliberal}

El actual declive de la democracia, que se expresa en la perdida de coherencia y legitimidad de sus instituciones como receptoras de la voluntad popular (veánse Crouch, 2004; Hermet, 2008; Jörke, 2008), está ligado a una idea elitista de la política, en la que la lucha ideológica es reemplazada por una «experticia» técnica que da forma a una gobernanza dominada por la tecnocracia neoliberal. Es lo que Zizek (2009b) sintetiza en el término pospolítica.

Con la pospolítica, las contradicciones sociales son alejadas del debate político para ser afincadas en lo que se podría llamar una negociación técnica de sostenibilidad entre actores sociales tradicionales (empresarios y sindicatos), grupos de expertos y Gobiernos. Una negociación en la que muchas veces recae la decisión final de diversos asuntos que atañen al conjunto de la sociedad, como el salario mínimo, tipos de empleos y contratos, seguro de desempleo, régimen de pensiones, política medioambiental. Así, grandes sindicatos, empresarios y lobbistas se convierten en agentes paraestatales no electos que condicionan la política económica gubernamental.

En esta misma línea, no está de más señalar otro ejemplo de la realidad que construye la pospolítica, en detrimento de la política democrática, en ámbitos como la sanidad y la educación pública. Afirman quienes defienden esta idea de la política, que el Estado solo debe dedicarse a ampliar la cobertura sanitaria o educacional sin inmiscuirse en quien lo haga y que fines persiga. Con ello, se oculta la confrontación política ímplicita en una decisión como esta. Se niega el debate de antagonismos politicos que dinamiza la sociedad.

El predominio de esta idea también ha supuesto la extensión de una construcción estatal $a d$ hoc a las ideas de libre mercado y derecho de la propiedad. Surge con ella una formulación neoliberal del Estado que consagra un tipo de libertad que favorece el poder de clase, la mercantilización de derechos sociales, los intereses del gran capital y la hostilidad hacia las organizaciones laborales (Harvey, 2007). Un tipo de libertad que resulta útil para consolidar los oligopolios económicos, la especulación financiera y la concentración de ingresos, lo que otorga un amplio poder a los dueños del capital - los mercados - para condicionar y oligarquizar la composición y el proceso de 
toma de decisiones del poder político. En este esquema, la soberanía popular pasa a ser un estorbo o un escollo que hay que sortear.

Este tipo de Estado también se sirve de cierta hostilidad discursiva hacia la dimensión soberana de la democracia. Líderes políticos, como la canciller alemana Ángela Merkel, han llegado incluso a señalar que la democracia debe someterse y ajustarse a los mercados (Merkel, 2014). Esta afirmación representa toda una declaración de guerra a la democracia, pues de ella se colige que las decisiones políticas, además de no responder al mandato popular, están abiertamente arbitradas por el poder económico. Por lo demás, esto está en línea con la teoría de la public choice, que asegura que la intervención política con objetivos sociales distorsiona la racionalidad del mercado (Streeck, 2011).

Una consecuencia directa de esta dinámica política se puede observar en la baja ponderación que la población otorga a sus gobiernos democráticos — no a la democracia-. Así, el grado de satisfacción con la democracia, que suele asociarse a la responsiveness o capacidad de respuesta de los Gobiernos a la voluntad popular (Morlino, 2009; 2015), muchas veces refleja la abismal lejanía entre gobenantes y gobernados. Es lo que se aparecia en los países de América Latina, donde solo un 38 \% de la población afirma estar satisfecha con el funcionamiento de la democracia (Latinobarómetro, 2015). Algo similar sucede en Europa, aunque en este caso la satisfacción con el funcionamiento de la democracia alcanza un 50 \% (European Social Survey, 2016).

Pero además, el ideario neoliberal ha infundido valores que han dificultado que su hegemonía sea contestada, como la defensa de la libre iniciativa individual, la libertad de enseñanza o el derecho a la propiedad privada sin limitaciones (Harvey, 2007). Para evitar que estos valores alienadores decaigan ante el miedo a la incertidumbre que abona la propia economía neoliberal, son reforzados con falsas y fantasmagóricas certidumbres, tales como el consumo masivo, el culto a la propiedad, el populismo punitivo, el crecimiento económico o la vorágine tecnológica. Ellas contribuyen a desvincular la realidad social de lo real. Como señala Zizek (2009b), se crea ese vacío que experimentan países donde reina el desorden, el deterioro ecológico y la miseria, mientras que sus informes económicos dicen que su economía es financieramente sana.

Ninguno de los valores que sostiene el ideario neoliberal —incluyendo sus refuerzos cognitivos - reconoce a la democracia como una infraestructura política de transformación social.

\section{El problema de la desigualdad social}

Como se advierte de un comienzo, la extensión global de la democracia en las últimas décadas coincide con el sostenido aumento de la desigualdad de ingresos y riqueza dentro y entre países. Una desigualdad que se ha defendido, desde los espacios de difusión ideológica neoconservadores (medios de comunicación, thinks thanks, escuelas de negocios, organismos económicos internacionales, élites financieras), como una estructura natural de la sociedad que permite optimizar el bienestar económico. Sin 
embargo, el aumento exponenecial de la desigualdad puede ser una de las principales causas del retroceso o declive de la democracia.

La democracia capitalista no ha dificultado el incremento de la desigualdad debido a que ha tenido una histórica tendencia a preferir la libertad —económica — antes que la igualdad. La falta de equilibrio entre estos elementos, que quedaron enfrentados tras la imbricación de la tradición liberal con la democrática (Mouffe, 2012), es su gran deficiencia. Su difícil conciliación es también la base del enfrentamiento entre las interpretaciones liberal y popular de la democracia. La primera enfatiza en la libertad individual, mientras que la segunda lo hace en la igualdad social.

Para el liberalismo contrarrevolucionario la igualdad era la antítesis de la libertad. Así lo entendieron Hamilton et al., (2004), quienes señalaron que la democracia, como sinónimo de igualitarismo, era contraria a la libertad. Específicamente, «una amenaza para la libertad económica tal como se concebía habitualmente entonces y, en particular, para el tipo de libertad representado por el derecho de propiedad" (Dahl, 2002: 4). Este temor también lo expresaba Tocqueville cuando postulaba que «mientras más democrático llegue a ser un pueblo, mayor parece ser el peligro para la libertad» (ibid:: 11). Tocqueville (1969) además sostuvo que la igualdad de todos los ciudadanos crearía una tendencia natural al conformismo y, a consecuencia de ello, desaparecería toda iniciativa privada. Por este motivo, para el liberalismo el gobierno debía estar sustentado en los principios de libertad y representación.

Pero la libertad liberal puede llegar a tener un cariz negativo cuando está asociada únicamente a la libertad económica y a un derecho de propiedad sin límites (Dahl, 2002). La libertad es negativa - defiende los privilegios- cuando no favorece una libre disposición de los recursos — materiales e inmateriales - y no propende al desarrollo igualitario de las capacidades de todos los individuos en la sociedad. La desigualdad aumenta como resultado «de un tipo determinado de libertad: la libertad de acumular unos recursos económicos ilimitados y de organizar la actividad económica en empresas dirigidas de manera jerárquica» (ibid.: 46). Esa desigualdad se puede convertir en estructural con la ayuda de una infraestructura pública que rigidice la estratificación social.

Hoy, por el contrario, igualdad y libertad se consideran elementos complementarios para el buen funcionamiento de la democracia (Merkel, 2014; PNUD, 2014; Morlino, 2015). No se entienden enfrentados, salvo que la libertad se conciba como una mera extensión del derecho a la propiedad y el libre mercado. Esta consideración, por lo demás, es compartida por los ciudadanos al relacionar la democracia a este binomio axiomático (Przeworski, 2010). Incluso, si es consultado, un individuo promedio tiende a privilegiar la igualdad sobre la libertad (véanse Montero y Morlino, 1993; Gómez et al., 2010).

La igualdad, entendida como libertad positiva, está vinculada a las condiciones socioeconómicas que hacen efectiva la igualdad política de todos los ciudadanos, una especie de igualitaria libertad que fomenta la participación en los asuntos políticos. Como explican Boix y Stokes «en un esquema de redistribución más equitativo de los ingresos se ganaría apoyo democrático (el apoyo del votante medio), en vez de uno en 
que la distribución fuera altamente desigual» (2003: 539). Una forma de comprobar la relevencia que esto tiene para la democracia, es cruzando y comparando los datos de participación electoral e interés por la política con el índice Gini de desigualdad. Al hacerlo se obtiene, como tendencia, que en los países menos desiguales la participación e interés por la política es mucho más alta que en los más desiguales (AlvaradoEspina, 2017).

Por consiguiente, para acercarse al ideal democrático se necesita avanzar en mayores grados de igualdad. Este es el factor que otorga la misma posibilidad de ejercer plenamente los derechos y las libertades políticas a los ciudadanos, sin que sean menoscabados por grupos privilegiados de ningún tipo (Marshall, 1997; Dahl, 2008). Para ello, es menester cierta simetría en las condiciones materiales de vida —acceso a la vivienda, desarrollo cognitivo, seguridad social—. Todos ellos son derechos sociales mínimos que garantizan una similar influencia de los ciudadanos en las decisiones de la política, expandiendo a la vez los valores de la democracia (Dahl, 2002; Inglehart, 2005). Esta es una ampliación de lo que Tocqueville (1969) denominó la igualdad de condiciones que permitía a cada individuo influir en la marcha de la sociedad política, en sus gobernantes y en los hábitos de los gobernados. Sin esa igualdad de condiciones, los derechos y libertades políticas se tornan irrelevantes para la conformación del poder político.

Así entendida, la igualdad —o libertad positiva — es un requisito fundamental para el autogobierno del pueblo, ayudando además a desactivar la prevaleciente alienación política de las sociedades postindustriales (Offe, 1990), al tiempo que potencia el rol emancipador que propugna el ideal democrático.

En virtud de este razonamiento, se puede establecer que mientras la libertad otorga a los individuos la oportunidad de reclamar sus derechos, la igualdad les asegura disfrutar de esa libertad sin tener que ceder en los mismos. Ambos tipos de libertad no están en conflicto ni sus valores fundamentales están enfrentados. Lo que sí parece estar en abierto conflicto con la libertad y la igualdad política es la libertad económica basada en el mercado, promovida por el ideario neoconservador, y que se reproduce debido a la actual concepción neoliberal del Estado.

\section{EL DOBLE DESAFÍO DE LA DEMOCRACIA}

En la era neoliberal las élites corporativistas se han servido de la economía de mercado y el relato pospolítico para difundir la idea de que vivimos en una sociedad que no está estructurada por la división social o de clases (Mouffe, 2012). Su triunfo ideológico ha sido vital para ampliar el dominio del capital en las demás esferas de la distribución social, gracias a que su base contrafactual —el mercado como actividad natural de las relaciones humanas - apenas ha sido contestada por las élites políticas en las democracias consolidadas (Przeworski, 2010). Con ello, exclusión, elitismo y desigualdad se han erigido en señas de identidad de la forma en que se estructuran las relaciones sociales, culturales, políticas y económicas, vaciando de contenido a la democracia. 
En este contexto, la democracia contemporánea se ha reducido a una mínima expresión de sus aspectos formales, consolidando su versión procedimental y elitista gracias a la privatización de las relaciones entre política y sociedad. Es lo que autores como Crouch (2004) han identificado como un retroceso a la etapa predemocrática. Así, su infraestructura se ha vuelto contradictoria con los dictámenes que fijan la realidad concreta de los individuos, siendo totalmente servil a lo real, que no es otra cosa que la práxis capitalista que construye la realidad social (Zizek, 2009b).

Por otra parte, la sociedad que prodiga el neoliberalismo no resulta compatible con los aspectos conformantes y sustantivos de la democracia por tres grandes motivos: a) la libertad económica neoliberal elitiza el proceso de toma de decisiones, haciéndolo cada vez más antidemocrático; b) el Estado neoliberal promueve un desarraigo de la economía de los ámbitos social y político, creando sensaciones de desasosiego e impotencia en los ciudadanos respecto a sus efectos materiales —el debate económico se aparta del conflicto político al cual pertenece-, y c) la economía neoliberal acrecienta todas las brechas de desigualdad (política, social, cognitiva, de ingresos, de género, de patrimonio), lo que a su vez (auto) excluye del sistema político a los individuos de menores recursos materiales. Este conjunto de motivos explicaría, entre otras cosas, la falta de conexión entre élites políticas y ciudadanía (espacio politizado) y de estos con los individuos desafectos (espacio despolitizado). Un fenómeno que incide en lo que Norris (2011) denomina déficit democrático, que es la tensión entre el ideal democrático y el juicio negativo sobre su desempeño.

Se puede afirmar, entonces, que el neoliberalismo es disfuncional a la democracia, en tanto que estructura la sociedad según una rígida jerarquía social que promueve tanto la violencia subjetiva como objetiva entre individuos y grupos. Una violencia que es subproducto de la desigualdad económica, social, política y cultural que fomenta su matriz ideológica, la cual no precisa de ningún principio democrático para funcionar ni legitimarse. De hecho, como advierte Klein (2007), a la economía neoliberal solo le basta un trauma o desastre - político, social, económico, natural— para imponer su lógica.

En definitiva, teniendo en cuenta el contexto estructural —ideología y desigualdad- que reproduce el neoliberalismo, la democracia se enfrenta a un doble desafío, si acaso se quiere evitar que su declive dé paso a regímenes residuales e ingobernables: por un lado, conseguir que estén debidamente representados todos los intereses, valores e ideas en las instituciones políticas y, por otro, que los resultados de sus procesos respondan efectivamente a las demandas mayoritarias de la sociedad.

\section{Referencias}

Alvarado-Espina, Eduardo. 2017. La calidad de la democracia en España y Chile. Un análisis a partir de la desigualdad social y el elitismo politico [tesis]. Jaime Ferri Durá (dir.), Universidad Complutense de Madrid.

Bachrach, Peter. 1973. Critica de la teoría elitista de la democracia. Buenos Aires: Amorrortu. 
Barreiro, Belén. 2015. La rebelión de las masas. Madrid: El País.

Battison, Robert. 2011. "The Democratic Recessions Has Turned into A Modern Zeitgeist of Democratic Reform». Open Democracy, 21-12-2011. Disponible en: https://bit.ly/2KMm4xp.

Beck, Ulrich. 1998. La sociedad del riesgo. Hacia una nueva modernidad. Barcelona: Paidós.

Best, Heinrich y John Higley. 2010. «Introduction: Democratic Elitism Reappraised», en Heinrich Best y John Higley (eds.), Democratic Elitism: New Theoretical and Comparative Perspectives. Leiden-Boston: BRILL. Disponible en: https://doi. org/10.1163/ej.9789004179394.i-230.6.

Bobbio, Norberto. 1986. "Democracia y pluralismo», Revista de Ciencia Politica, 8 (1-2): 127-137.

Boix, Carles y Susan C. Stokes. 2003. «Endogenous Democratization», World Politics, 55 (4): 517-549. Disponible en: https://doi.org/10.1353/wp.2003.0019.

Cohen, Joshua. 2001. «Democracia y libertad», en John Elster (ed.), La democracia deliberativa. Barcelona: Gedisa.

Collier, David y Steven Levitsky. 1997. «Democracy with adjectives. Conceptual Innovation and Comparative Research", World Politics, 49: 430-451. Disponible en: https://doi.org/10.1353/wp.1997.0009.

Crouch, Colin. 2004. Posdemocracia. Madrid: Taurus.

Dahl, Robert. 1961. Who Governs? democracy and power an american city. New Haven: Yale University Press.

Dahl, Robert. 1992. La democracia y sus críticos. Barcelona: Paidós.

Dahl, Robert. 1997. La poliarquí. Participación y oposición. Madrid: Alianza.

Dahl, Robert. 2002. Democracia económica. Barcelona: Hacer.

Dahl, Robert. 2008. La igualdad politica. Buenos Aires: Fondo de Cultura Económica.

Dahl, Robert. 2012. La democracia. Barcelona: Ariel.

Dahl, Robert, Giovanni Sartori y Fernando Vallespín. 1999. «El futuro de la democracia", Claves de razón práctica, 97: 4-9.

Diamond, Larry, Juan J. Linz y Seymour M. Lipset. 1990. Democracy in Developing Countries: Latin America, Volume Four. Boulder: Lynne Rienner.

Diamond, Larry. 2003. «¿Puede el mundo entero ser democrático?», Revista Española de Ciencia Politica, 9: 9-38.

Downs, Anthony. 1973. Teoría económica de la democracia. Madrid: Aguilar.

Dunn, John. 2005. Setting the People free. The story of Democracy. Londres: Atlantic Books.

Easton, David. 1965. Framework for Political Analysis. Chicago: University of Chicago Press.

European Social Survey. 2016. How satisfied with th way democracy works in country. Análisis online. Disponible en web: http://nesstar.ess.nsd.uib.no/webview/.

Everson, Michelle. 2000. «Beyond the Bundesverfassungsgericht: on the necessary cunning of constitutional reasoning», en Zenon Bankowski and Andrew Scott (eds.), The European Union and Its Order: The Legal Theory of European Integration. Oxford: Blackwell. 
Finer, Samuel E. 1966. Imperio Anónimo: estudio del «lobby» en Gran Bretaña. Madrid: Tecnos.

Frankenberg, Günter. 2011. «Teoría Crítica», Academia, 9 (17): 67-84.

Fundación Alternativas. 2015. Informe sobre la democracia en España. Reformular la politica. Madrid: Catarata.

Giddens, Anthony. 1999. La tercera vía. La renovación de la socialdemocracia. Madrid: Taurus.

Gómez, Braulio, Irene Palacios, Manuel Pérez Yruela y Ramón Vargas-Machuca. 2010. Calidad de la democracia en España. Barcelona: Ariel-Planeta.

Gramsci, Antonio. 1975. Cartas desde la cárcel. Madrid: Cuadernos para el diálogo.

Habermas, Jürgen. 1989. «La soberanía popular como procedimiento», Cuadernos Políticos, 57: 53-69.

Habermas, Jürgen. 1992. Further Reflections on the Public Sphere, en Craig Calhoun (ed.), Habermas and the Public Sphere. Cambridge: MIT Press.

Habermas, Jürgen, 1999. La inclusión del otro. Estudios de teoría política. Barcelona. Paidós.

Hamilton, Alexander, James Madison y John Jay. 2004. El Federalista X. México DC: Fondo de Cultura Económica.

Harvey, David. 2007. Breve historia del neoliberalismo. Madrid: Akal.

Hermet, Guy. 2008. El invierno de la democracia. Barcelona: Los libros del lince.

Huntington, Samuel P. 1991a. The Third Wave. Democratization in the Late Twentieth century. Norman, Oklahoma: University of Oklahoma Press.

Huntington, Samuel P. 1991b. El orden politico en las sociedades en cambio. Barcelona: Paidós.

Inglehart, Ronald. 2005. «Modernización y cambio cultural: la persistencia de los valores tradicionales», Quadens de la Mediterrània, 5: 21-31.

Jörke, Dirk. 2008. «Post-democracia en Europa y América Latina», Revista de Sociología, 22: 141-156. Disponible en: https://doi.org/10.5354/0719-529X.2008.14488.

Keane, John. 1992. Democracia y sociedad civil. Madrid: Alianza.

Kelsen, Hans. 1980. Esencia y valor de la democracia. México DC: Editora Nacional.

Klein, Naomi. 2007. La doctrina del shock. Barcelona: Paidós.

Laclau, Ernesto y Chantal Mouffe. 1987. Hegemonía y estrategia socialista. Hacia una radicalización de la democracia. Madrid: Siglo XXI.

Latinobarómetro. 2015. Análisis online. Disponible en: https://bit.ly/2smQNcz.

Levitsky, Steven y Lucan Way. 2015. «The Myth of Democratic Recession», Journal of Democratic, 26 (1): 45-58. Disponible en: https://doi.org/10.1353/jod.2015.0007.

Lijphart, Arend. 1995. Sistemas electorales y sistemas de partidos: un estudio de 27 democracias, 1945-1990. Madrid: CEPC.

Lindblom, Charles E. 1997. Politics and Markets. Nueva York: Basic Books.

Mainwaring, Scott y Aníbal Pérez-Liñán. 2015. «La democracia a la deriva en América Latina», Postdata, 2: 267-294.

Mair, Peter. 2015. Gobernando el vacio. La banalización de la democracia occidental. Madrid: Alianza. 
Marshall, Thomas H. 1997. "Ciudadanía y clase social», Revista Española de Investigaciones Sociológicas, 79:297-344. Disponible en: https://doi.org/10.2307/40184017.

Marx, Karl y Frederich Engels. 1987. El manifiesto comunista. Madrid: Ediciones Endymión.

Merkel, Wolfgang. 2014. "Is capitalism compatible with democracy?», Zeitschrift für Vergleichende Politikwissenschaft, 8: 109-128. Disponible en: https://doi. org/10.1007/s12286-014-0199-4.

Montero, Juan R. y Leonardo Morlino. 1993. "Legitimidad y democracia en el sur de Europa», Revista Española de Investigaciones Sociológicas, 64: 7-40. Disponible en: https://doi.org/10.2307/40183697.

Morlino, Leonardo. 2009. "La calidad de la democracia», Claves de Razón Práctica, 193: 26-35.

Morlino, Leonardo. 2015. «¿Cómo analizar las calidades democráticas?», Revista Latinoamericana de Política Comparada, 10 (1): 13-36.

Mouffe, Chantal. 1999. El retorno de lo politico. Buenos Aires: Paidós.

Mouffe, Chantal. 2012. La paradoja democrática. El peligro del consenso en la politica contemporánea. Barcelona: Gedisa.

Norris, Pippa. 2011. Democratic Deficit. Critical Citizens Revisited. Nueva York: Cambridge University Press. Disponible en: https://doi.org/10.1017/CBO9780511973383.

O’Donnell, Guillermo. 1989. «Transiciones, continuidades y algunas paradojas», Cuadernos Politicos, 56: 19-36.

O’Donnell, Guillermo, Osvaldo Iazzetta y Jorge Vargas Cullell. 2003. Democracia, desarrollo bumano y ciudadanía. Reflexiones sobre la calidad de la democracia en América Latina. Rosario: HomoSapiens.

Offe, Claus. 1990. Contradicciones en el Estado del Bienestar. Madrid: Alianza.

Peters, B. Guy. 2003. «Dismantling and rebuilding the Weberian state», en Jack Hayward y Anand Menon (eds.), Governing Europe. Oxford: Oxford University Press. Disponible en: https://doi.org/10.1093/0199250154.003.0007.

PNUD. 2014. Auditoría de la democracia. Más y mejor democracia para un Chile inclusivo. Santiago de Chile: LOM.

Przeworski, Adam. 1991. Democracy and the Market. Cambridge: Cambridge University Press. Disponible en: https://doi.org/10.1017/CBO9781139172493.

Przeworski. Adam, Michael Alvarez, José A. Cheibud y Fernando Limongi. 1996. "What Makes Democracies Endure?», Journal of Democracy, 7 (1): 39-55.

Przeworski, Adam, 2010. Qué esperar de la democracia. Limites y posibilidades del autogobierno. Buenos Aires: Siglo Veintiuno Editores.

Rawls, John. 1996. El liberalismo político. Barcelona: Crítica.

Roberts, Kenneth M. 2002. «Social Inequalities Without Class Cleavages in Latin America's Neoliberal Era», Studies in Comparative International Development, 36 (4): 3-33. Disponible en: https://doi.org/10.1007/BF02686331.

Rosanvallon. Pierre. 2006. La contre-démocratie. La politiqua à l'âge de la defiánce. París: Éditions du Seuil. 
Ruiz, Carlos. 1992. «Las teorías de la democracia y el concepto de lo político», Revista de Ciencia Politica, 14 (1-2): 5-21

Sartori, Giovanni. 1987. Teoría de la democracia 1. El debate contemporáneo. Madrid: Alianza.

Sartori, Giovanni. 2003. ¿Qué es la democracia? México: Taurus Alfaguara.

Sartori, Giovanni. 2008. La democracia en 30 lecciones. Madrid: Taurus.

Schaap, Andrew. 2007. «Political Theory and the Agony of Politics», Political Studies Review, 5: 56-74. Disponible en: https://doi.org/10.1111/j.1478-9299.2007. 00123.x.

Schmitter, Phillipe. 2015. «Crisis and Transition, But Not Decline», Journal of Democracy, 26 (1): 32-44. Disponible en: https://doi.org/10.1353/jod.2015.0004.

Schumpeter. Joseph. 2008. Capitalism, socialism and democracy. Nueva York: Harper Perennial Modern.

Sen, Amartya. 2006. El valor de la democracia. Barcelona: El Viejo Topo.

Smith, Martin. 1997. «El pluralismo», en David Marsh y Gerry Stoker (eds.), Teoría y métodos de la ciencia política. Madrid: Alianza.

Stiglitz, Joseph E. 2011. El malestar en la globalización. Madrid: Santillana.

Streeck, Wolfgang. 2011. "The Crises of Democratic Capitalism», New Left Review, 71: 5-29.

Thatcher, Mark y Alec Stone Sweet. 2003. The Politics of Delegation. Londres: Frank Cass \& Co. Ltd.

The Economist. 2016. Democracy Index. Disponible en web: https://bit. ly/2DV7Yr4.

Tilly, Charles. 2007. Democracy. Cambridge: Cambridge University Press. Disponible en: https://doi.org/10.1017/CBO9780511804922.

Tocqueville de, Alexis. 1969. La democracia en América. Madrid: Guadarrama.

Touraine, Alain. 1991. «¿Qué es hoy la democracia?», Revista Internacional de Ciencias Sociales, 128: 273-282.

Vargas Cullell, Jorge. 2012. «La calidad de la democracia y el estudio comparado de la democratización», en Gerardo L. Munck y Sebastián Mantilla (eds.), La calidad de la democracia: perspectivas desde América Latina. Quito: CELAEP.

Zizek, Slajov. 2009a. En defensa de la intolerancia. Madrid: Sequitur.

Zizek, Slajov. 2009b. Sobre la violencia. Seis reflexiones marginales. Barcelona: Paidós.

Presentado para evaluación: 1 de marzo de 2018.

Aceptado para publicación: 28 de junio de 2018.

\section{EDUARDO ALVARADO-ESPINA}

ealvaradoespina@gmail.com

Consultor e investigador asociado del Centro de Ingeniería Organizacional de la Universidad de Chile. Es licenciado en Ciencias Políticas y de la Administración por la 
Universidad de Concepción (Chile). Máster en Diplomacia y Relaciones Internacionales por la Escuela Diplomática y la Universidad Complutense de Madrid. Máster en Análisis Político y doctor en Ciencias Políticas por la Universidad Complutense de Madrid. También es editor de la revista digital Política Crítica. Autor de más una treintena de artículos publicados en revistas científicas y periódicos electrónicos de España y Chile, además de dos recientes capítulos de libros: «Representación, actores políticos y open government ¿¿Una democracia deliberativa?», en Relatos culturales de la crisis: comunicación y crítica politica, y «La desigualdad como condición estructural para un modelo de análisis de la calidad de la democracia», en Conocimiento para la equidad social: pensando Chile globalmente. Sus principales líneas de investigación son: teoría y calidad de la democracia, comportamiento y liderazgo político, élites políticas y cultura política en América Latina. 